\title{
Hindi Print Media Content Analysis Of Bhopal Gas Tragedy: In The Context Of Reflect And Effect Study Of Media On Society ARMENDRA AMAR
}

\begin{abstract}
The 1984 Bhopal Gas Leak tragedy has been classified as one of the World's major Industrial accidents of the $20^{\text {th }}$ century, recorded post 1919 , by a United Nations Report. This tragedy killed thousands of people and maimed thousands. Union Carbide subsidiary pesticide plant released approximately 40 tonnes of Methyl Isocyanate (MIC) gas which went on to touch the lives of more than 500,000 people of the city. In a way, even after it immediately killed and maimed in thousands, it is still a continued disaster as the generations exposed to the toxic gases have been consistently showing up signs of physical and mental deformity. This gruesome event's impacts on society are beyond time and space. The crucial question that renders is that how media dealt with the situation and to what extent it affects the everyday life of masses. This study came into initiation when the researcher visited the Methyl Ico-Cynate gas-affected area of Bhopal. During the pilot study, the researcher saw that people of the affected place were living in inadequate conditions. Thus, a concern piqued the interest of the researcher, and evoked an indispensible question: Is media fulfilling its responsibility as the fourth pillar of society in times of chaos and devastation, towards the public? For examining his queries researcher has taken renowned print media outlet's articles of Bhopal gas tragedy as the content of the analysis. Hence on the basis of Hindi print media content of Bhopal gas disaster the researcher has taken the initiative to search appropriate answers to questions which examine the role of media after the tragic occurrence has taken place in society.
\end{abstract}

Key words: Hindi print media, Bhopal Gas Leak tragedy, media representation, Methyl Isocyanate, MIC, Social responsibility of media, Positive media 


\section{Introduction}

Bhopal gas tragedy as world's one of the worst industrial tragedy

"Next morning saw people walking up with burning eyes and lung disorder. Citizens of Bhopal started panicking and running from here to there to save their lives. This morning was horrendous as all roads and lanes were cramped with dead bodies of people and animals. Hospitals were full of patients. Patients desperately sick and in many cases dying”, some of the gas survivors were recalling their experiences of that horrible night of $2^{\text {nd }}$ December 1984 (The Bhopal Reader: Remembering twenty years of world's worst industrial disaster, 2004).

After the tragedy, the Indian Council for Medical Research (ICMR) established the Bhopal Gas Disaster Research Centre (1985). The institute classified the affected persons in three categories, i.e., severe, moderate and mild by mortality parameters. About 80,021 persons were classified under these three categories. The population of 15,931 was called an unexposed and controlled population, (Dhar, 2013). These data are quite attentive to indicate Bhopal gas tragedy as world's one of the worst industrial disaster.

Glimpses of the world wide print media coverage of Bhopal gas tragedy

Very few research studies have been conducted on the representation of the Bhopal gas disaster in Media. A Content Analysis of media coverage done by American media about the gas tragedy concluded that most of the coverage or study represented the western or American perception.

Chen Lou (2011) from Scripps college of communication of Ohio University wrote thesis entitled "News Framing of the 1984 Bhopal Gas Leak in India and the 2010 BP Oil Spill in the Gulf of Mexico: A Content Analysis of The New York Times and The Washington Post Coverage." Lou (2011) focused on the theoretical perspectives and how print media frame news related to disastrous events. In the thesis, the author conducted a comparative study of the print media coverage of two tragic events: Bhopal gas tragedy 1984 and the BP oil spill in the Gulf of Mexico, 2000. The researcher had taken the contents of two newspapers "The New York Times" and "The Washington Post" as materials to study and investigate. The researcher decided to inquire the period of the first five months from the date of the disaster in both the cases.

The New York Times and The Washington Post published 89 stories related to Bhopal gas leakage from December 3, 1984 to May 4, 1985. On the other hand, 296 new stories were published by both the newspapers for BP oil spill from $20^{\text {th }}$ April 2010 to $21^{\text {st }}$ September 2010. The study also examined how the news coverage of the two events having the same patterns differed in the tone of the headline, utilization of sources, and how responsibility was attributed.

Lou (2011) also included the significant role of mass media in informing and educating the public. He emphasized on "why" U.S. media represented the incidents having a similar nature differently to their audience. Researchers had to undergo the framing theory and press nationalism in their study to formulate a theoretical framework.

Researcher Lou (2011) quoted (Dynes 1970) news coverage of disasters attracted a considerable audience, griped people's imagination, heightened the sense of the importance of human action, and facilitated emotional identification for the strengthening of his study. The thesis consisted of three hypotheses with one objective. The first hypothesis was related to the overall coverage of both accidents concerning how news was presented; the second hypothesis attempted to explore the quotient of responsibility in media 
coverage; third and last hypothesis was concerned about the usages of different news sources while covering the same type of news.

The whole dissertation of Lou (2011) was based on the content analysis of news articles for five months. An analysis of the study showed that the news coverage of Bhopal gas (leakage) disaster diminished during the five months in both the newspapers relatively to the BP oil spill disaster.

Chen Lou studied the perspectives of both the disastrous events, thereby, looking at various dimensions like the aftermath of the disaster, background information, and assistanceguidance with lawsuit and compensation.

Lou (2011) conducted a pilot study of all articles of both the newspapers and confirmed each article addressed one specific topic, for instance, one article covered the anguish of the survivors', while the other article covered issues causing environmental degradation. The researcher had encoded every article differently, for instance, the tone of the headline, the theme of the article, nature of coverage and much more.

The conclusion of the Lou (2011) dissertation confirmed that American newspaper had covered more about the BP oil Spill disaster than the Bhopal gas tragedy. Newspapers had also used two different sources for the coverage of the disaster. For disaster, which occurred in the Gulf of Mexico, newspaper agencies used federal government sources; on the other hand, for world's worst industrial disaster they became dependent on corporate sources to frame the news.

According to Lou (2011) BP oil spill was a matter of nationalism and proximity for American people rather than an incident like Bhopal gas disaster (India). So the newspapers had given more weight to the BP oil spill.
Media of U.S.A drafted the news about Bhopal gas disaster in such a way that it took away the attention of the public from their responsibilities and gave a very causal description according to the lawsuits. It indicated that American news media failed to fulfill their obligation towards the Indian society. Instead, they focused on American Society which was severely affected by the Mexican gulf accident. Although Lou (2011) drafted his dissertation on the American context, it gave clarity about the concepts and ideas about how news was framed about disastrous events.

Based on this case study, the author attempted to understand the various aspects of Indian print media which covered Bhopal gas tragedy. Within a limited scope of the present study, it was indicated that the media was able to make its presence felt by covering the various dimensions of the Bhopal gas tragedy. The study aimed to evaluate two points 1) Was Hindi print media able to fulfill its status of a watchdog during the incident and aftermath the world's worst industrial disaster?, and 2) to examine the theory of "social responsibility of media" in the context of Bhopal gas tragedy print media.

\section{Social responsibility of media}

Media's Social Responsibility is one of the four normative theories along with the other three theories, Authoritarian, Libertarian and Marxist theory. The normative theory of media was propounded by Peterson, Wilbur Schramm, and Fred in the 1950's.

The philosophy of social responsibility depicts the duties of media towards the society; these duties are the collective guidelines of ethics through which Media resolves the conflict and response in tragic times. Social responsibility of media is related to the public opinion and audience reaction on major social interests.

Pro-people and society-friendliness are important approaches to the media social responsible theory. The theory stated that 
freedom of media always comes with specific responsibilities towards society.

Prof. Denis Mc Quails (2010) has given some concrete concepts about media social responsibilities in his book 'Mass communication theories.' Mc Quails (2010) wrote that "Media should always show their gratitude towards the society. Media should be unbiased and focus on objectivity with balance approaches".

Media should endeavor an appropriate platform to the public where they can express their needs and views on a particular issue. With the concluding note, Mc Quail (2010) wrote that "media should be liable and accountable to the society." In the past few decades, the opinion of society has changed towards the media. Now, the media is not merely reflective of society.

\section{Methodology}

The revelation of the nature and characteristics of print media representation in the context of the Bhopal gas tragedy was the central theme of this paper. In this paper content analysis was useful for exploring the in-depth reports, opinions, and reviews. Secondary data were used as the main Source for the content analysis method.

Study of Riffe \& Freitag (1997) about content analyses study in Journalism \& Mass Communication Quarterly found that it increased from $6.3 \%$ of all articles in 1971 to $34.8 \%$ in 1995 - nearly a six-fold increase. Study of Riffe \& Freitag (1997) gave the required impetus to adopt the content analysis for this study.

\section{Sampling framework}

Thirty articles have been selected for content analysis for the study. These thirty articles have been selected from three Hindi print media outlets. These articles were placed in descending order till $3^{\text {rd }}$ December 2016.
Sample articles were select from following Print Media Outlets i.e. three Hindi Newspapers Dainik Bhaskar, Hindustan, Jansatta. Latest ten articles have been selected from each newspaper in descending order from 3rd Dec 2016.

The researcher didn't set a time frame to select the Bhopal gas news from these media outlets because Bhopal gas tragedy was not the contemporary issue. It had been happening around three decades ago. But newspapers frequently publish the Bhopal gas tragedy stories especially on its anniversary date. Thus researcher has decided to take ten articles from each newspaper in descending order.

Hindi is the most significant language in India. Henceforth, the significance of the Hindi was one of the core reasons behind to choose Hindi newspapers for the study. Geographical location of Bhopal in the Hindi Heartland of India was the second reason to measure the impact of Hindi newspapers on the life of Bhopal gas victims.

The researcher has adopted two is to one ratio for selecting newspapers. Here two newspapers related to Bhopal edition, and the third one was from Delhi edition. According to the Audit bureau circulation list (2016), top two daily Hindi newspapers of Madhya Pradesh Dainik Bhaskar and Patrika were selected in the study as the local edition. Meanwhile, Jansatta, Hindi newspaper of Express group was included in the research as the Delhi edition.

Manual code sheet and categories of articles for content analysis

1) Date of Article: Represent the time frame frequency of news articles

2) Geographical Location: Proximity of articles from ground zero

3) Type of Article: Represent different format of articles 
4) Nature of Article: Represent different purpose of articles

5) Impetus of Article: Emphasis on the different dimensions

6) Size of Article (Total number of words: Article length

7) Total number of sentences: Article length

8) Total number of metaphor (Related to objectives): Keywords of article

9) Total number of sentence-relatedto metaphor: Keywords sentences of article

10) Total number of quoted sentence: Referred/ cited sentences in articles

\section{Metaphors related with objectives}

1) Victims/Survivors, 2) Severely, 3) Struggle,

4) welfare, 5) Disaster/Tragedy/Tragic, 6) Diseases/ Disorder, 7) Protest, 8) Rehabilitation/ Remediation, 9) Relief, 10) Hazardous/Toxic/ Contaminated, 11) Justice, 12) Compensation/
Settlement, 13) Responsibility/Liability, 14) Social-Political-Economical, 15) Safety

\section{Likert scale}

The researcher has used the Likert scale parameter to measure the ordinal value of the data. The researcher cited the Vagias,Wade $\mathrm{M}$ (2006), Likert- type scale response anchors tables for this study. There were two types of the values were measured from the 5 Point Likert Scale.

Level of responsibility and satisfaction was measured as following i.e. Not all responsible/satisfactory (1-20\%), Slightly responsible/ satisfactory (21-40\%), Moderately responsible/ satisfactory (41-60\%), Very responsible/satisfactory (61-80\%), Extremely responsible/ satisfactory (81-100\%)

Table 2: Combined statistical table of three Hindi newspapers articles (Dainik Bhaskar, Patrika, and Jansatta)

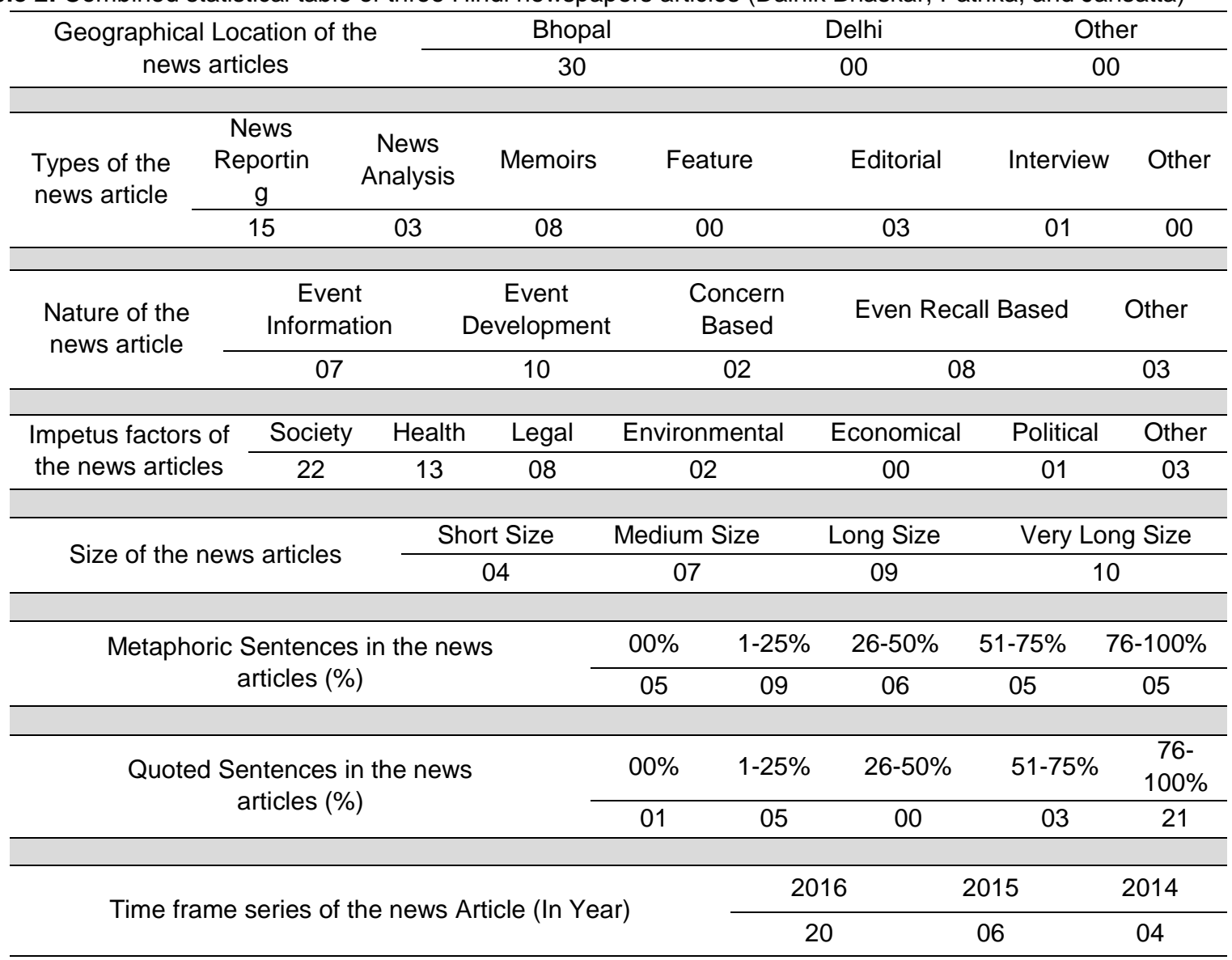




\section{Interpretation, statistical and graphical analysis of data of thirty articles from three Hindi newspapers}

The above table was the combined representation of the data of thirty articles of Bhopal gas tragedy of three Hindi newspapers. Dainik Bhaskar, Patrika, and Jansatta were included for the study. Patrika and Dainik Bhaskar have their local edition of Bhopal, but Jansatta publishes from New Delhi. Despite of the Delhi edition, Jansatta had all ten news of the series from Bhopal dateline. Jansatta had taken approximately two years for ten articles. Though, these three newspapers had collectively taken two years for thirty Bhopal gas tragedy articles.

Concentrating on the ground reporting Hindi newspaper represented the tragedy with diverse types of format like news reporting (15), memoirs (8), news analysis (3), editorial (3) and interview(1). So, the natures of these thirty articles were diverse. Articles gave the event information (7), event development stories (10), also recall the memories experiences of the victims (8) and published NGO or some concern report related (2) with others stories (3). Thus, it could be said that the type and nature of the Hindi newspaper articles were inter connected to each other. In the impetus of the article category researcher acquired the clear command of societal factor (22) in statistical finding. Average of $66 \%$ represented to the verysatisfying section on the five-point Likert scale. Apart from the dominance of societal factor, health (13) and legal factor (8) were in top factors of the articles.

Average of Metaphoric words related sentences in the article was the next category of code sheet. Where, researcher found the cumulative average of $36.8 \%$ of Hindi newspapers articles. The average of $36.8 \%$ lied into to moderately satisfied column at five-point Likert scale. Average of quoted sentences in the article was the last category of code sheet. Surprisingly the cumulative average of quoted sentences thirty articles of three Hindi newspapers was very high of $76.4 \%$. And the average of $76.4 \%$ comes in the very satisfying section at five-point Likert scale.

On the basis of data it could be stated that Dainik Bhaskar and Patrika were very much active to cover the Bhopal gas tragedy with local their edition. Meanwhile, Jansatta was little slow for its ten articles. These Hindi newspapers were not only very frequent but also scrutinize the issue from all the directions. They not only did formal reporting on the issue but also raised the prime developments aftermath of the tragedy. The Hindi Newspapers had taken interviews, published memoirs and highlighted the survey report in their publication. So, the Hindi newspapers were very rich in content with quick reporting of the tragedy. 
Table3. Assessment of core factors of Hindi newspaper articles at five-point Likert scale. Level of Responsibility of Impetus factors at 5 Point Likert Scale

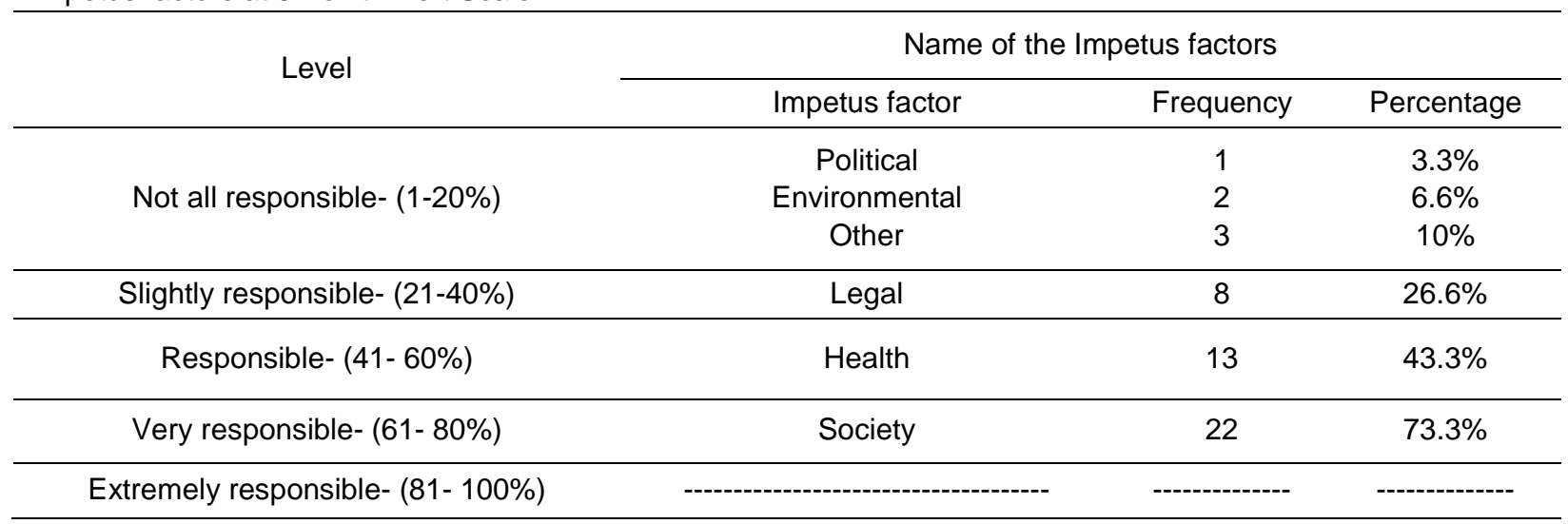

The above table is the representation of impetus factor of Hindi newspaper articles on the parameter of five-point Likert scale of responsibility. According to the findings of the study, Hindi newspapers were quite responsible (73.3\%) to raise the societal struggle of survivors. Hindi newspapers also reflected the health problems of victims in a responsible way with 43.3\%. Hindi Newspaper also raised the legal complexity of victims in a slightly responsible manner. On the other hand, figure reflected that newspapers didn't portray the political, environmental issue responsibly.

\section{A critical analytical view on the Hindi newspapers representation of Bhopal gas tragedy}

Hindi newspapers representation of Bhopal gas tragedy reveals a varied approach. The local edition of Dainik Bhaskar and Patrika were quick in their approach while New Delhi Jansatta took more than year one for its ten articles of the Bhopal gas tragedy. In the Jansatta articles focus were observed on the health of Bhopal gas survivors, their justice journey and also the protest of sufferers in their articles. Jansatta also published a series on the Bhopal gas tragedy like Trasadi ka Malba and Trasadi ki Kadiyan in 2014. The Dainik Bhaskar and Patrika were very quick to cover the Bhopal gas tragedy with local editions. These Hindi newspapers were frequent and also scrutinized the tragedy issue from all the directions. For an example in one article "petition ki tisri pidhi ka dard or hakikat" Hindi newspaper Patrika attempted to explore generation long pain of the Bhopal gas victims.

Meanwhile, Dainik Bhaskar focused on the immediate effect of the gas tragedy in its articles. Some of its Stories like "Yeh hai Duniya ki sabse Badi trasadi ka asar" and "Gas trasadi: Aaj bhi hare hain 32 saal purane jakhm" further strengthened the observation of researcher about Dainik Bhaskar representation on the third generation pain of tragedy survivors.

Thus, Patrika and Dainik Bhaskar not only performed formal reporting but also represented the important difficulties which were emerged aftermath of the tragedy. Representation of gas tragedy was reflected with the interviews, memoirs and many survey reports. Henceforth on the satisfactory note Hindi newspapers had given the all round performance in representation of Bhopal gas tragedy event.

\section{Discussion and Conclusion}

Soumya Dutta (2011) has written a paper on the role of media entitled the 'social responsibility of India in Indian democracy'. Dutta (2011) initially criticized the Indian media for not fulfilling its social responsibilities; but in the next part of the study, she appreciated the Indian 
media and wrote that "time to time media successfully fulfilled the role of a watchdog in the society." She also emphasized that more efforts were required by the media for the betterment of society. The researcher of this study also found almost same kinds of views, data, results and figures in his readings and fact findings. The media responsibility is not only related to the social terms but also in the political and economic terms.

This study has its focus on the print media content analysis of a tragedy reporting. Paper also scrutinized the features of a different form of media articles of Hindi newspapers. The study identifed the nature and core factors of the print news of Bhopal gas tragedy. The study also analyzed the perspective of news articles from different dimensions.

A major and important finding of this study was that the media was the main source of stressrelief forum of the victims. The results of the study highlighted the importance of print media in today's era of new media. The basic form of media (Print) is still effective in minimizing the "stress and loneliness" during and after a tragedy. Thus, finally it could be concluded that media partly fulfilled its social responsibilities towards the society aftermath of the disaster situation and have to require more efforts.
Armendra Amar, Department of Journalism and Mass communication, Dev Sanskriti Vishwavidhyalaya. Email ID: armendra.amar@dsvv.ac.in 


\section{References:}

Perse M. Elizabeth (2001). Media Effects and society. Universityof Delaware, Lawrence Erlbaum, Publishers Mahwah, new jersey London.

Wimmer RogerD \&DominicikJosephR.(2011). Mass MediaResearchAnIntroduction, New Delhi: CengageLearning.

KumarRanjit (2012). Research Methodology A Step by Step Guide for Beginners. Australia: Pearson Education.

O' Shaghnessy Michal \& StadlerJane (2010). Media and society. Australia, Newzland: Oxford Publication.

Sarangi Satinath \& Morehouse ward \& Hanna Bridget (2005). The Bhopal Reader: remembering twenty years of the world's worst industrial disaster. New York: TheApex Press.

Cullian.P (2001). A case study of Bhopal gas accident. London: Environment Toxicology and Human Health-Volume-I.

Sharma Shalini (2015). Indian media and the struggle for justice in Bhopal. Publication journal social justice, spring-summer edition.

Tomar.R (2014). Understanding Counterhegemony and Feminist Approach to Bhopal Movement. Bonn: Responsible development in polycentric world inequality citizenship, and Middle classes. $14^{\text {th }}$ EADI General Conferences.

Griffin \& Michaelson (2015). A new model for media content analysis. The Institute of public relation.

Marshal McLuhan (2003) Understanding Media: The Extensions of ManMcQuail, Denis (2010). McQuail's Mass Communication Theory, New Delhi:Vistaar Publications

Dutta, S. (June 2011). Social responsibility of India in Indian democracy. Global Media Journal Indian Edition/ Summer Issue.

Lou, C. (2011). News framing of the 1984 Bhopal gas leak in India and the 2010BP oil spill in the Gulf of Mexico: A content analysis of The New York Timesand the Washington Post coverage (Unpublished doctoral dissertation). OhioUniversity.
Barange, S. (2016, December 2). Gas trasadi: Aaj bhi hare hain 32 saal puranejakhm Dainik Bhaskar.

Yeh hain sabse bhayavah Chemical attack, jab maut ki nind so gaye the lakhon log.(2016, October 16). Dainik Bhaskar.

Bhudolia, A. (2016, August 27). Aapdaon se jude jokhim ko rokne hua discussion.Dainik Bhaskar.

Gas piditon ke liye aavas ki alag se koi yojana nahi, 16 din me aayen 70000 form. (2016, June 13). Dainik Bhaskar.

Banrange, S. (2015, December 2). Bhopal gas trasadi story. Dainik Bhaskar.

Gas piditon ke liye aavas ki alag se koi yojna nahi, 16 din me aye 70000 form. (2016, June 13). Dainik Bhaskar.

Banrange, S. (2015, December 2). Bhopal gas trasdi story. Dainik Bhaskar.

Gas kaand: Desh me yahan bhi hue Bhopal jaise hadse, jaa chuki hai kayi ki jaan. (2015, December 1). Dainik Bhaskar.

Yeh hai Duniya ki sabse badi trasdi ka asar. (2015, December 1). Dainik Bhaskar.

Budhwaar ko Bhopal gas trasadi ke tiis saal pure. (2014, December 2). Dainik Bhaskar.

Sabse Bhayvah chemical attack, jab maut ki nind so gaye the lakho log. (2016, December 3). Dainik Bhaskar.

Bhopal gas tragedy $32^{\text {nd }}$ anniversary victim's family slam America Narendra Modi, Shivraj Singh Chouhan. (2016, Dec. 3). Jansatta.

Bhopal gas kaand: Anderson ko bhagane ke liye purv collector evm SP par case. (2016, Nov. 21). Jansatta.

Bhopal gas kaand ke liye Dow chemical ko jababdeh thahrane ko white house me yachika. (2016, June 12). Jansatta.

Bhopal gas mamle me phir adalat pesh nahi hui Dow chemical. (2015, Dec. 20). Jansatta.

Bhopal gas piditon $\mathrm{kr}$ janmjaat vikrit bachhon ka ilaaz karaye sarkar. (2015, December 3). Jansatta.

Trasadi ki Kadiyana. (2014, Dec. 8). Jansatta. 
Bhopal gas tragedy. (2014, Dec. 6). Jansatta.

Trasadi ka malba. (2014, December 3). Jansatta.

Bhopal gas trasadi ke tiss saal: nahi hata carbide ka jahrila kachra. (2014, December 3). Jansatta.

Nauriyal, N. (2016, December 3). Bhopal gas kaand: Hadsa garibo ki basti me hua isliye study nahi hui. Patrika.

Sarvariya, B. (2016, December 3). Badhali se gujar rahe hain gas rahat hospital, mashine kha rahi hain Dhul. Patrika.

Pandey, S. (2016, December 3). Piditon ki tisri pidhi ka dard or hakikat. Patrika.

Jahan Lashe Bichin thi waha jindgi ki khusiyan dhundh rahi hain lakhon aankhe (2016, December 3). Patrika.

Kumar, S. Char December 1984 ko in khabaron se bhare the akhbaar, 12 hazaar log the lapta, (2016, December 2). Patrika.

Upadhyaya, R. Tum Mujhe bacha lo dekhna main tum sabko ko bacha lunga (2016, December 2). Patrika.

Sarvariya, B. 32 saaal baad aayi yaad, ab hoga piditon ka aise ilaaz (2016, December 2). Patrika.

Kumar, S. Syah raat ke daravane manjar ke mahanayak bane the ye chehare (2016, December 1). Patrika/

Riffe, D., \& Freitag, A. (1997). A content analysis of content analyses: twenty-five years of Journalism Quarterly. Journalism and Mass communication Quarterly, 74, 873-882 